\title{
Las competencias jurisdiccionales en el gobierno y la administración aduanera en el Río de la Plata: La comisión secreta de Francisco Ximénez de Mesa en la Real Aduana de Montevideo en 1786
}

María Evangelina Vaccani"

Fecha de recepción: 30 de marzo de 2020. Fecha de aceptación: 30 de septiembre de 2020

\section{Resumen}

Palabras clave

Real Aduana de Montevideo competencias jurisdiccionales comisión

El presente trabajo tiene por objeto conocer la realidad política e institucional de las Reales Aduanas del Río de la Plata. Se busca comprender el sistema político de la monarquía española a fines del siglo XVIII y principios del XIX. Se estudia la comisión secreta y por vía reservada de Francisco Ximénez de Mesa en la Real Aduana de Montevideo en 1786. Las competencias jurisdiccionales de los asuntos del Real Erario en manos del Superintendente de Real Hacienda, Francisco de Paula Sanz, permitieron organizar tal pesquisa. En 1788 , tras la reestructuración de la superintendencia, se retoman los informes de la comisión originando la revisión de los estados contables, llevando a la quiebra al administrador Antonio Quintana y Lasso de la Vega. Para este caso se consultaron expedientes de la sección Criminales del Archivo General de la Nación, documentación de Reales Órdenes, reglamentos y ordenanzas vinculados a la organización administrativa del ramo aduanero.

Jurisdictional powers in the government and customs administration in the Rio de la Plata: the secret commission of Francisco Ximénez de Mesa in the Royal Customs of Montevideo in 1786

\section{Abstract}

Keywords

Royal Customs of Montevideo jurisdictional power commission
The present paper aims to learn about the political and institutional reality of the Royal Customs of the Río de la Plata. It seeks to understand the political system of the Spanish monarchy in the late $18^{\text {th }}$ and early $19^{\text {th }}$ centuries and analyzes the secret commission of Francisco Ximénez de Mesa in the Royal

* Becaria doctoral de la Universidad Nacional de Tres de Febrero. Instituto de Estudios Históricos. La Plata, Buenos Aires, Argentina. Email: evivaccani@gmail.com 
Customs office of Montevideo in 1786. The jurisdictional powers of the Royal Treasury in the hands of the superintendent of the Royal Treasury, Francisco de Paula Sanz, allowed organizing such an investigation. In 1788, after the restructuring of the superintendence, the commission reports were resumed, causing the revision of the financial statements, leading to the bankruptcy of the administrator Antonio Quintana Lasso de la Vega. For the study of this case, files from the Criminal section of the Archivo General de la Nación, documentation of Royal Order, regulations and ordinances linked to the administrative organization of the customs branch were consulted.

\section{Introducción}

El objetivo general de este trabajo será aportar elementos para conocer el sistema político sobre el que se dio la relación entre la monarquía y los territorios del Río de la Plata a finales del siglo XVIII. Dentro de este objetivo se busca una aproximación a la realidad administrativa y jurisdiccional de la Real Hacienda virreinal. En este recorrido se propone un acercamiento a la realidad institucional en la que se dio gobierno a los asuntos aduaneros en la región rioplatense, analizando las competencias y excesos de los servidores ${ }^{1}$ frente a los asuntos de gobierno del erario real.

En relación a la renovación de estudios sobre los erarios reales y su notable vigencia en el campo historiográfico, se hace hincapié en la incorporación de nuevas propuestas de análisis que ponderan los aspectos cualitativos, donde se reflotan las tramas institucionales y su componente jurisdiccional. ${ }^{2}$ Dentro de estas propuestas se presentan los aspectos administrativos que hacen al gobierno de la Real Hacienda, entendido como un conjunto de tribunales y jueces con determinadas competencias en los asuntos fiscales. En este trabajo se propone ver al sistema político de la monarquía a partir de la acción de distribuir justicia. El Rey, como cabeza del gobierno, reconocía cuatro ámbitos de actuación: justicia, gobierno, hacienda y guerra. Estos ámbitos se determinaron por un proceso de cambio institucional sustentado por las leyes, por el iuscommune, las instancias de justicia y el arbitrium judicial. Dentro de este sistema de gobierno las superposiciones de poderes y los conflictos de competencias resultan las características principales de la administración de justicia en todo el ámbito jurisdiccional de la Monarquía Hispánica.

Para ello se profundizará el análisis de la concepción de la Monarquía administrativa, pues aporta elementos que permitan conocer el conjunto de orientaciones de la acción de gobierno que se ven puestas en jaque, al mismo tiempo que se intentan llevar a delante. El estudio del diseño institucional sobre el que operó la administración de las reales aduanas en el Río de La Plata nos aproxima a conocer las orientaciones de gobierno que primaron y sus alcances. Contemplando esta conceptualización se propone conocer el sistema de hacienda real desplegado en el virreinato, sabiendo que en el proceso de demarcaciones de competencias hacendarias estas se aplicaron sobre la marcha de los asuntos que las requerían. Se observa que en un mismo distrito convergieron múltiples autoridades. La corona buscó dar autonomía jurisdiccional al nuevo Virreinato y para ello fue dotándolo de un andamiaje político e institucional propio, distribuyendo competencias y delegando poderes en sus magistrados. Para contrarrestar el peso de las múltiples autoridades entre las que se destacan el virrey, el Superintendente de Hacienda -en función desde 1778 hasta 1788- y los oidores -desde 1785-, entre otras, se fueron delimitando sus
1. La utilización de la noción de servicio posibilita despojarnos de las connotaciones weberianas que implica estudiar al funcionario/ burócrata borbónico y ver la evolución de sus prácticas en relación a la normativa y las exigencias que el cargo imponía. A mitad de camino de estas propuestas Brendecke y Martin Romera (2017: 29-30) proponen analizar la profesionalización de los oficiales reales en la modernidad a partir del desarrollo de habitus, incorporando el análisis de la evolución de sus prácticas y contemplando las condiciones que el ejercicio del servicio imponía.

2. Para un ejemplo de estos trabajos consúltese Wasserman (2018). 
3. Las propuestas que versan sobre la monarquía administrativa dan cuenta de que los servidores obtenían oficio a comisión, desplegando sus poderes en pos de concretar objetivos políticos mientras que el rey se reservaba el derecho de suprimir el servicio, si veía alterado el orden político (Mannori, 2007: 136).

4. (En adelante, RO de Intendentes). Real Ordenanza para el establecimiento e instrucción de Intendentes de ejército y provincia en el Virreinato de Buenos Aires año de 1782 de orden de su Majestad.

5. El administrador Antonio Quintana y Lasso de la Vega era natural de Mallorca aunque había pasado la mayor parte de su vida en una ciudad cercana a Málaga. Entre sus antecedentes al servicio del rey figuran haber sido Regidor propietario y haberse desempeñado en el Regimiento de Milicias como Coronel, por lo tanto llegó a la vacancia en la Aduana sin contar con experiencia en la administración (Bentancur, 1985: 74). funciones de gobierno definidas bajo las delegaciones de justicia. Proceso que estuvo jalonado por los conflictos y pleitos de competencias.

Las intenciones de la corona fueron crear instancias de gobierno administrativas que contrarrestaran los poderes polisinodiales, como un posible obstáculo a las exigencias fiscales y militares. Se observa que los magistrados habrían patrimonializado su oficio, obstaculizando el despliegue de poder real. Para contrapesar esta realidad se buscó una organización alternativa al "oficio" y sobre nuevos resortes institucionales se montó el modelo por "comisión". Con este último, el poder delegado jurisdiccionalmente se hacía a título procuratorio y revocable en cualquier momento, posibilitando los ajustes ante los desequilibrios y excesos de los servidores. ${ }^{3}$

En el Río de la Plata esto se tradujo en la instalación de la Superintendencia de Real Hacienda como instancia superior de gobierno en la administración y fiscalización de los recursos del erario real. Esta quedó bajo el control de la Secretaría de Estado y del Despacho Universal de Indias, a cargo de José de Gálvez. Bajo este esquema se montaron y administraron las tesorerías aduaneras en la región rioplatense. Los servidores/administradores, como interlocutores de las políticas de la Corona, desarrollaron sus estrategias y acciones donde se observa que continuaron ejerciendo su jurisdicción, cometiendo excesos que se dirimieron por la vía contenciosa.

El caso de la comisión secreta en la Real Aduana de Montevideo de 1786 permite profundizar el conocimiento de los fundamentos del sistema político que dio sustento al gobierno y supervisión de los servidores hacia fines del siglo XVIII y principios del XIX. Dicho sistema operó bajo un marco normativo que se fue ajustando a medida que las urgencias y necesidades lo determinaron. La pesquisa en la aduana permite cotejar la forma de administración y develar cómo se procedió en una compleja trama institucional y jurisdiccional. Se destaca el rol del administrador de la Aduana de Buenos Aires quien, en representación del gobierno de la Superintendencia de Real Hacienda, se desempeñó como juez comisionado, inspeccionando los estados de las cuentas de la tesorería. La clave puesta en los servidores y las competencias otorgadas habilita a exponer una veta más de la compleja trama de poderes concurrentes, propia de las sociedades de Antiguo Régimen. Atendiendo la actividad judicial -con sus diferentes agentes y tribunales- con las estrategias que en dicha configuración adoptan, los justiciables y pleiteantes, siempre dentro de sus posibilidades.

En el Virreinato del Río de la Plata el modelo administrativo hacendario se plasmó con la implementación de la Real Ordenanza de Intendentes de $1782 .{ }^{4}$ El establecimiento de la Junta Superior de Real Hacienda y la centralidad de la figura del Superintendente delimitaron las competencias jurisdiccionales de los asuntos administrativos, fiscales y comerciales en la región. La RO de Intendentes estableció como primera instancia de justicia a la Junta Superior de Real Hacienda. Ante el armado y dotación de un complejo sistema institucional, para evitar oposiciones a las decisiones de la Junta, el superintendente optó por llevar a cabo, por vía reservada, la comisión en la Aduana en 1786. Este proceso fue reabierto y en 1788 se decretó la quiebra del administrador Antonio Quintana y Lasso de la Vega ${ }^{5}$ por malversación de caudales.

Uno de los problemas que enfrenta este tipo de investigación es la falta de documentación referida al accionar de la Junta Superior de Hacienda en la Aduana de Montevideo. Para superar esta limitación se toma el expediente judicial de la quiebra del administrador que, basándose en el informe de 
la comisión secreta realizada por Francisco Ximénez de Mesa, ${ }^{6}$ logra tomar conocimiento de la malversación y formas con las que se administró la tesorería. Este informe y expediente judicial es triangulado con las ordenanzas y los marcos legales que atendieron el funcionamiento de la Real Hacienda, al menos en la corta vida de la Superintendencia entre los años 1782 y 1788 . Finalmente, se presentan los ajustes y las acciones sobre el gobierno de la Aduana de Montevideo en particular y la hacienda virreinal en general.

En suma, el estudio de la experiencia administrativa de la aduana de Montevideo posibilita aproximarnos a la realidad del gobierno hacendario que operó en el Río de La Plata. A continuación se propone esbozar los marcos teóricos que explican las formas de gobierno en los asuntos fiscales. Y sobre ellos ver cómo se dio la administración de los asuntos aduaneros, presentando las circunstancias que llevaron a la realización de la comisión sobre la tesorería a cargo de Quintana, para finalmente exponer los resultados y los ajustes que se sucedieron luego de comprobar la malversación de fondos en la Aduana.

\section{Los resortes del poder y el sistema político en siglo XVIII, un debate en construcción}

En este apartado pasaremos revista sobre las concepciones que han abordado el sistema de poder de la monarquía y especialmente sus implicancias en el sistema de gobierno de los erarios reales en el siglo XVIII. Como punto de partida se consideran las críticas dadas al paradigma estatalista y sobre las que se están revisitando las explicaciones relativas a la relación de la monarquía y sus territorios de ultramar (Garriga, 2004). Por ello se relevarán las preguntas y problemas que buscan reflexionar en torno al lugar de América, buscando alternativas a las explicaciones consolidadas bajo el paradigma colonial (Jumar, 2017).

El desarrollo político de América en el siglo XVIII parte de un diagnóstico sobre una autoridad debilitada y ha sido explicado por el avance y el despliegue de políticas reales que buscaban fortalecer el poder real bajo el común denominador de las reformas borbónicas. ${ }^{7}$ Nuevos enfoques han propuesto revisar los alcances de estas políticas y sostienen que el reformismo borbónico es una construcción historiográfica que se ha naturalizado como categoría, al punto de que se ha aplicado a cualquier momento de la vida hispanoamericana. ${ }^{8} \mathrm{La}$ evolución singular de los espacios americanos ha evidenciado que las políticas desplegadas no fueron unidireccionales y la reformulación del gobierno se dio con antelación a la Guerra de los Siete Años, entre 1756 y 1763, e incluso se remonta a fines del periodo Habsburgo (Storss, 2013).

Las interpretaciones que han nutrido el enfoque reformista y sus consecuencias versan sobre dos líneas; una de ellas pondera el absolutismo y sus alcances fiscales en el corto, mediano y largo plazo, y la otra retoma el pacto de sujeción entre la corona y los súbditos (Kraselsky, 2012). Resaltamos que esta última interpretación ha reposicionado a los actores americanos en el centro de la escena política. De aquí que se propone ver a las elites americanas como interlocutores de las políticas reales y apreciar la negociación como sustento de la dominación en América. ${ }^{9}$

La atención puesta en la evolución económica de los erarios reales en el período borbónico llevó a profundizar el estudio de los resortes institucionales que posibilitaron el despliegue de medidas. Así las urgencias militares de la corona
6. Francisco Ximénez de Mesa ocupó el puesto en la administración de la Real Aduana de Buenos Aires entre 1779 y 1788 ; de origen malagueño, antes de arribar a Buenos Aires había sido Alcalde en Tabasco, Nueva España. Su fama y renombre se dio por el extenso proceso que atravesó, al igual que Quintana, luego de decretarse su quiebra en septiembre de 1788 (Vaccani, 2019).

7. Al respecto puede consultarse Lynch (1967), Burkholder y Chandler ([1977] 1984), Pietschmann (1985), Brading (1990) y Gelman (2000).

8. El dossier coordinado por José Joaquín Pintos Bernal y Ernest Sánchez Santiró (2016), propone reflexionar en torno al alcance de la categoría reformismo borbónico con el fin de profundizar los marcos explicativos para comprender la forma de operar de los actores en los espacios americanos. Para el caso concreto de la historiografía argentina ver Jumar (2016).

9. A partir del estudio de las bases jurídicas del sistema fiscal Irigoin y Grafe (2008) analizan el papel de los situados, reconstruyendo las bases legales que sustentaron la negociación entre la corona y sus interlocutores americanos. Para el Río de la Plata, consultar el reciente trabajo Wasserman (2020), donde analiza la reconfiguración hacendaria entre 1767 y 1777 , el papel de real situado y los acreedores locales observando los mecanismos que se institucionalizaron para sostener la defensa de Buenos Aires. 
10. Sin contemplar las críticas al paradigma estatalista se observa que las interpretaciones sobre el desempeño de los servidores han versado sobre el "funcionario borbónico" definido a partir de la concepción weberiana de racionalidad burocrática (Socolow, [1978] 1991: 258). El desempeño de los funcionarios ha sido explicado por el fenómeno de la corrupción, observándose su accionar a partir de la tensión entre la normativa y la praxis en el buen gobierno dentro del marco de un EstadoNación (Pietschmann, 1985: 11-12). Otra propuesta es ver la mutua conexión entre los intereses reales y sus agentes, bajo la corrupción como componente sistémico (Moutoukias, 1988).
11. Reunidos en la Red Columnaria, este grupo de investigadores aborda metodologías e intereses compartidos a partir de nodos temáticos. Como eje de articulación propone nodos fronterizos, donde se compartía una cultura política y administrativa, e invita al estudio integral y comparativo de los diferentes espacios que conforman el poder del mundo ibérico. Disponible en Internet: https://www.um.es/ redcolumnaria/red-columnaria/. Consultada el: 24 de abril de 2020. determinaron las necesidades fiscales, convirtiendo a las cuestiones bélicas y a los asuntos del erario real en dos aristas clave que explican el cambio institucional y permiten conceptualizar a la monarquía como un estado fiscal militar (Torres Sánchez, 2012 y 2013). Aunque este enfoque sigue siendo tributario del paradigma estatalista tiene la virtud de ponderar la variable económica del sistema de poder.

Buscando explicar el papel de los actores americanos en las tramas institucionales de la Real Hacienda la clave puesta en el Hispanus Fiscus posibilitó superar la dicotomía entre la negociación y la tensión, reparando en el sistema político en el que operó la Real Hacienda de la monarquía en su desarrollo territorial (Clavero, 1982/83). Bajo esta visión los actores americanos institucionalizados encontraron puntos en común y congruentes con los intereses de la Corona. El funcionamiento del gobierno hacendario se dio bajo la delegación de competencias jurisdiccionales, las cuales recayeron sobre los magistrados. Como alternativa a la visión estatalista, la clave puesta en las dinámicas institucionales y su componente jurisdiccional permite comprender las acciones de los servidores. Estos ya no como funcionarios que actuaban bajo un "tipo ideal profesional", sino como jueces y partes al servicio del gobierno hacendario. ${ }^{10}$

Como se advierte, el paradigma jurisdiccional es lo que subyace a las conceptualizaciones dadas al sistema de poder de la monarquía. Se observa que el diseño institucional bajo magistraturas del siglo XVIII se caracterizó por el desarrollo de organismos judiciales con competencias específicas. A cada sector de gobierno concerniente a los asuntos del fisco, abasto, comercio, caminos, entre otros, se agregan los asuntos de la administración de justicia en un sentido propio, quedando subordinados a un consejo soberano pero todos recíprocamente autónomos (Mannori, 2007: 132). Sobre este modelo se apoyó el funcionamiento de la Real Hacienda en el Virreinato del Río de la Plata.

A la hora de explicar y conceptualizar a la monarquía en el paso del siglo XVII al XVIII se han hecho grandes avances para comprender las dinámicas de poder y las relaciones que caracterizaron a la monarquía hispánica. La conceptualización de monarquía compuesta para el siglo XVII (Elliott, 1992) permitió cuestionar la centralidad del poder a partir de la naturaleza compuesta del mismo, reparando en una única soberanía que daba unidad territorial. Como crítica a esta visión se destaca el énfasis puesto en los aspectos constitucionales que no han logrado captar el impacto de las normativas en los súbditos, lo que ha sesgado el rol de los actores en las tramas de poder (Conrad y Gallego, 1996). Buscando superar estas limitaciones, se propuso el estudio de las redes atlánticas, los centros de poder y la circulación de las elites, lo que reposiciona a los actores en el centro de la escena política, permitiendo reconstruir las dinámicas imperiales (Yun Casalilla, 2009).

Examinando los aspectos globales de las tramas de poder la conceptualización de monarquía policéntrica propone ver múltiples centros de poder, donde cada uno participa activamente de las decisiones y la cohesión está dada por la uniformidad religiosa. La propuesta policéntrica plantea la multiterritorialidad en pos de contrarrestar la idea de nación que subyace en la visión compuesta. A su vez, los historiadores adeptos al policentrismo advierten sobre la convivencia de múltiples jurisdicciones que actuaban para contrarrestar los poderes locales. ${ }^{11}$ Esta visión propone recuperar lo local para ver cómo se inscribía ello en lo global. Y propone mirar la evolución de las relaciones de poder de las monarquías modernas no en términos comparativos sino por dinámicas de poderes concurrentes y yuxtapuestos (Barriera, 2006: 206). 
Como se observa lo que se sobrepone a estas conceptualizaciones es el paradigma jurisdiccional, en tanto explicación filosófica y jurídica del sistema de poder y ejercicio del mismo. La cultura jurisdiccional aporta una visión institucional de la práctica social del poder y su vinculación con el discurso del derecho. Se toma la iusrisdictio como base del derecho y se contempla un orden institucional plural, donde la máxima función de gobierno del rey es la distribución de justicia y su poder encuentra límites en la arraigada tradición religiosa (Agüero, 2006). La dimensión política del sistema se definía en sus marcos jurisprudenciales fijando las instancias y las competencias atribuidas a las instituciones y a los actores que la conformaban. Así las ordenanzas, los estatutos y las sentencias jurídicas buscaban sostener el equilibrio del orden corporativo, en pos de construir la equidad "dando a cada uno lo que por derecho le pertenece" (Moriconi, 2011: 40).

Con el arribo de los Borbones al poder, tras la Guerra de Sucesión, se dio un paulatino proceso de ampliación de los ámbitos de actuación de poder en materia de justicia, gobierno, hacienda y guerra. Observando el desarrollo global de la real hacienda se aprecia que se buscó un control más exhaustivo de los recursos fiscales, y para ello se fueron perfilando instituciones idóneas. Tales acciones pueden ser definidas por la aparición de una monarquía administrativa que, por medio de nuevas instancias de gobierno, buscó contrarrestar el poder de las jurisdicciones tradicionales, sorteando las instancias de negociación política en los múltiples cuerpos polisinodiales. ${ }^{12}$ Para ello se buscó montar un gobierno más ejecutivo que, junto a la vía de reserva y ministerial, concentró las decisiones sobre los asuntos del erario real manteniendo las jurisdicción como marco legal, cuestión que permitió evitar la acción unidireccional del juez.

En las nuevas tramas institucionales que se detallaron en el siglo XVIII, como en el modelo Habsburgo, los servidores obtuvieron prerrogativas reales que se tradujeron en competencias jurídicas. Así los actores americanos frente a los asuntos de gobierno definieron sus acciones entre los marcos legales y la praxis, modelando las prácticas y las acciones ante las urgencias y los avatares del gobierno real. ${ }^{13}$

Articulando estas reflexiones al estudio aquí propuesto en el Río de la Plata la organización hacendaria y su gobierno quedó supeditado a la figura del Superintendente, con ello se buscó crear un contrapeso político al accionar del Virrey (Kraselsky, 2017). Esta política se tradujo en un ordenamiento territorial y de demarcación de nuevas jurisdicciones fiscales, de forma definitiva con la RO de Intendentes de 1782. Ante el cambio institucional operado los servidores reales transformaron su poder de oficio en poder de comisión. Es decir que la Corona estableció una delegación de poder a comisión y anulable, que continuó siendo sometida a los procesos de jurisdicción (Mannori, 2007: 132-134). Con ellos se buscaba contrarrestar los desequilibrios y las fallas en el sistema administrativo y fiscal.

Se observa que en dicho proceso de ordenamiento hacendario los conflictos y los excesos de jurisdicción no estuvieron ausentes. En tanto, en el Río de La Plata la organización hacendaria se da de forma paulatina y cambiante en la primera década de equipamiento político institucional virreinal, donde los ajustes, los ensayos y los errores quedaban a la vista de los conflictos presentados. La comisión en la aduana de Montevideo posibilita una puerta de entrada al funcionamiento del sistema político, a las acciones de los servidores y a las formas de gobierno hacendario que se sostuvieron y que serán esbozadas en las páginas siguientes.
12. La corriente de Historia del Derecho Administrativo propone una genealogía del poder; a partir del caso francés observa la evolución de la cultura jurídica, buscando ver el paso del Estado de policía a la monarquía administrativa en la modernidad y su transformación hasta la administración (Mannori y Sordi, 2001). Para el caso de la monarquía hispánica consultar Garriga (1997).

13. En el caso novohispano se observa esta dinámica en el estudio de la Junta Superior de Real Hacienda. El análisis contrasta el uso normativo con los casos en los que actuó la Junta como supremo tribunal en sucesivos periodos de cambios institucionales entre 1787 y 1821 (Galván Hernández, 2018). 


\section{Delimitando competencias jurisdiccionales: la administración de las reales aduanas}

14. El concepto hace referencia a la integración de la región en el Río de la Plata a partir del desarrollo comercial a lo largo del siglo XVIII, (Jumar, 2012). Con la instalación de las aduanas se integraron los aspectos administrativos y fiscales en la región (Vaccani, 2019).

15. El Reglamento de 1778 dio forma definitiva a la organización comercial de larga distancia en la región del Río de la Plata. Desde la fundación de la ciudad de Buenos Aires se estableció la ruta ultramarina con la Península. El comercio se desarrolló desde 1622 a través de navíos de registro, práctica que se extendió al siglo XVIII dando lugar al crecimiento mercantil del complejo rioplatense. (Continúa en página 45).

16. Entre los ramos de aduanas figuran en la masa común las Alcabalas y Almojarifazgo aplicados a las operaciones mercantiles, los Reales Quintos y rentas aplicadas a contratos públicos. Los fondos eran de libre disposición en gastos administrativos, de sueldos o para ser transferidos a la tesorería principal. Los ramos particulares eran el Derecho de Sisa destinado a los gastos en fortificaciones (Vaccani, 2019: 36-37).

17. Fernández estuvo de Contador naval en varias plazas, como Ferrol, Cádiz y Cartagena. Fue comisario de la Real Armada en Valencia, Alicante, Cádiz y Orán. Se integró a la expedición de Cevallos al Río de la Plata en 1776. (Continúa en página 45).

18. De origen malagueño, en el Río de la Plata se desempeñó como administrador del Real Monopolio de Tabaco entre los 1777-1783. Luego ocupó la Superintendencia, hasta que fue relevado por el pase de jurisdicción de esta al virrey, y se le asignó la Intendencia de Potosí. (Diccionario Biográfico Electrónico, $\mathrm{s} / \mathrm{f})$.

19. Los magistrados ejercían jurisdicción frente a los asuntos de hacienda, limitando las atribuciones judiciales de la Audiencia y el Tribunal de Cuentas. Solo dependían de la Superintendencia General de Indias (Domínguez Orta, 2014: 213259 y Castejón, 2017: 795-797).

20. Entre los años 1663 y 1672 funcionó en Buenos Aires la primera Real Audiencia, la misma fue resistida por los poderes locales -cuestión que explica su corta vida.

21. El Tribunal de Cuentas estaba formado por José Antonio Hurtado y Sandoval como Contador Mayor -era sevillano y había sido vista en la Aduana porteña. (Continúa en página 45).
La organización de la estructura aduanera sobre el complejo portuario rioplatense $e^{14}$ responde a la definitiva reglamentación que habilitó a los puertos de Buenos Aires y Montevideo bajo el Reglamento y Aranceles para el Comercio Libre de España a Indias de $1778.1{ }^{15} \mathrm{El}$ establecimiento de las reales aduanas en los puertos de Buenos Aires el 2 de febrero de 1778 y de Montevideo el 10 de marzo de 1779, tuvo como fin dar un orden administrativo a las rentas reales que conformaron el ramo de aduanas. ${ }^{16}$ En una primera instancia la organización del gobierno de la Real Hacienda estuvo a cargo del Intendente Manuel Ignacio Fernández. En dicho proceso Fernández fue concentrando competencias y fue nombrado Superintendente de Real Hacienda y Ejército del Virreinato. En materia de asuntos aduaneros fue quien instrumentó la reglamentación, ordenó y supervisó a los servidores frente a las dependencias aduaneras (Domínguez Orta, 2016). ${ }^{17}$

Con la RO de Intendentes del 28 de enero de 1782 los asuntos de gobierno y de administración competentes a las cuestiones fiscales y comerciales quedaron bajo la exclusiva jurisdicción de la superintendencia, a cargo de Francisco de Paula Sanz. ${ }^{18}$ La consecuencia inmediata fue el cese de los jueces oficiales quienes ejercían jurisdicción sobre los pleitos fiscales, atribuciones que pasaron a los intendentes de cada provincia. Los intendentes asumieron exclusiva actuación sobre todos los asuntos que, por razones fiscales, requirieron la intervención de la justicia. Los fallos de los intendentes tenían la instancia de apelación en la Junta Superior de Real Hacienda que representaba la primera instancia. ${ }^{19}$

Aquí la Intendencia de Ejército y Hacienda de Buenos Aires se ubicó como sede del gobierno de la Superintendencia y bajo su jurisdicción territorial y fiscal quedaron las aduanas reales. El ordenamiento hacendario de los asuntos fiscales y comerciales quedó en manos del Superintendente, cercenando la competencia del Virrey, el Tribunal de Cuentas y la Real Audiencia pretorial de Buenos Aires, reinstalada en $1785 .^{20}$

Bajo esta estructura de gobierno se buscaba dar una correcta administración y hacer al gobierno de los reales erarios más ejecutivo. En Buenos Aires se fueron complejizando las tramas institucionales y los conflictos no tardaron en aparecer. Se repara que otras instituciones fueron dando forma al gobierno hacendario y tomaron notable participación en tales asuntos. Encontrando la Superintendencia contrapesos a sus decisiones administrativas y contenciosas (Rees Jones, 1987).

En 1780 se instaló en Buenos Aires el Tribunal Mayor de Cuentas, que absorbió y complejizó las tareas de la Contaduría Mayor de la gobernación de Buenos Aires y de las gobernaciones del Paraguay y del Tucumán establecidas en 1767. El Tribunal, conformado por tres contadores, ejercía la jurisdicción privativa para tomar y fenecer todas las cuentas de todo el Virreinato rioplatense, obteniendo autonomía de su homónimo limeño (Mariluz Urquijo, 2000: 131-132). José Mariluz Urquijo indicó que el atraso de los estados contables y la puesta en marcha de esta instancia superior obstruyó el desempeño de sus contadores, ocupados en ponerse al día con los retrasos y el desorden de las cuentas. La marcha de los asuntos parece dar un giro en 1785 cuando el nuevo contador, Alejandro de Ariza, presenta un informe a la Superintendencia exigiendo que se entreguen las cuentas atrasadas de las tesorerías. ${ }^{21}$ 
Fijada así la jurisdicción sobre los estados contables de las tesorerías, los contadores mayores del Tribunal de Cuentas, José Antonio Hurtado Sandoval y Francisco Cabrera, solicitaron a la Junta Superior de Real Hacienda que diese razón del estado de las cuentas del Virreinato. Se registraba un faltante de 87 cuentas entre las que se encontraban cinco de las Aduanas de Buenos Aires -entre 1780-1784- y dos de la Aduana de Montevideo -de 1783-1784.

Para aquel entonces Buenos Aires había completado su estructura de gobierno y la reinstalación de la Real Audiencia vino a complejizar la situación. ${ }^{22}$ Como lo indicó Ricardo Zorraquín Becú, las bases del establecimiento de la Audiencia se hicieron bajo las instrucciones de 1661, ello generó conflictos al no ser contemplados los arreglos jurisdiccionales de la RO de Intendentes de 1782. Los oidores "habían perdido toda intervención en los pleitos del fisco y en todos los juicios contenciosos administrativos, que desde 1783 corrían a cargo de los intendentes con apelación a la Junta Superior de Real Hacienda" (Zorraquín Becú, 1981: 170). A su vez, esto cercenó el accionar del Tribunal de Cuentas que perdió la instancia de ejecución de cuentas por la vía contenciosa. En esta trama las tensiones entre la Superintendencia y el Tribunal cobraron notoriedad, fue así que los Contadores Mayores decidieron someter a revisión y esclarecimiento las dudas que versaban en torno a las atribuciones y las competencias de cada parte del gobierno hacendario.

El Tribunal de Cuentas solicitó a la Junta Superior de Hacienda revisar el artículo 214 de la RO de Intendentes, para esclarecer y delimitar la jurisdicción contenciosa para la ejecución de cuentas. ${ }^{23}$ El citado artículo establecía que bajo esta ordenanza cesaban las funciones del Tribunal en lo que respecta a proceder en los juicios de cuentas, quedando ellas en manos de los Intendentes. Si el Tribunal necesitaba tomar alguna decisión superior para fenecer y cerrar los estados contables debía remitir su consulta a la Junta Superior.

Mientras las consultas corrían y se daba curso a las presentaciones de las partes en disputas por la competencia, la Superintendencia comenzó a actuar en la ejecución de las deudas atrasadas. Así como la Audiencia contaba con facultades para controlar la administración de la justicia creando instancias de pesquisa con la figura de comisionado, la Junta Superior de Hacienda establecía instancias con facultades homónimas. La figura de juez pesquisador o juez comisionado tenía competencias limitadas y temporarias, que habilitaban al servidor a llevar adelante una investigación puntual para la que había sido designado (Zorraquín Becú, 1981: 186).

En materia de hacienda y bajo lo regulado por la RO de Intendentes en el artículo 19 se establece la competencia de los intendentes para fijar comisión:

Y como que los Intendentes deben estar enterados de los abusos que haya en los Pueblos de su territorio, podrán instruir de ellos á los expresados Jueces de residencia ó pesquisa, con toda reserva y secreto; y éstos y los demás Comisionados tendrán obligación por lo mismo de noticiar y presentar sus comisiones á los Intendentes-Corregidores de la Provincia donde fueren destinados, pues les debe constar la autoridad y jurisdicción con que se hallen asistidos, y para su libre exercicio ha de preceder que les presten el uso y auxilios dispuestos por derecho (RO de Intendentes Art. 19)

Estas comisiones se fijaban en caso de que el intendente no pudiera vigilar en persona el desempeño de sus servidores y evitar que se cometieran abusos. En tal situación uno de los medios utilizados fueron las visitas, así al "hallarse
22. Se desconoce la composición de la Junta Superior bajo el gobierno del Superintendente Sanz. Como advierte el Artículo 3 de la RO de Intendentes, con la instalación de la Real Audiencia en 1785 su estructura se complejiza incorporándose su Regente y un oidor designado por el mismo Superintendente.

23. "En las privativas funciones que por varias leyes recopiladas están concedidas á los Tribunales y Contadurías de Cuentas de Indias, nada sustancial ha de innovarse para con los erigidos en Buenos Aires; pues aunque he resuelto darles nueva planta uniformándolos en lo posible y conveniente con mi Real Tribunal y Contaduría Mayor de Cuentas de estos Reinos por haber cesado los motivos que obligaron á dictar en parte la leí 39 título 15 libro 3, les quedan, sin embargo, aquéllas expeditas según y como se declaran en las Ordenanzas que para su buen gobierno he aprobado con la fecha de ésta. En cuya virtud será uno de los especiales cuidados de los Intendentes que los Ministros de Real Hacienda Contadores y Tesoreros, así Generales, como Principales y Foráneos, y los demás Administradores, ó Generales, ó Particulares de qualquiera ramo de mi Real Hacienda, formalicen, ordenen y justifiquen sus Cuentas con arreglo á lo dispuesto en la ya citada Instrucción práctica que ha formado la Contaduría General de Indias, á excepción, en quanto a Administradores, de los de la Renta del Tabaco, [...] Y en las ocurrencias en que, por duda ú otra qualquiera razón, necesite el mencionado Tribunal de Cuentas decisión superior, consultará á aquella Junta de Real Hacienda, á quien también reservó esta facultad, y la de conocer privativamente en los casos de que tratan las leyes $36,37,63,65,84$ y 88 del título 1 libro 8 , guardando en el modo y la substancia lo que ellas disponen" (RO de Intendentes, Art. 14). 
24. RO de Intendentes, Arts. 20 y 21.

25. En relación a la justicia ordinaria en base a las facultades de competencias jurisdiccionales del virrey, diferencia la justicia ordinaria y la delegada indicando en las Partidas III, 4.1: "Que los que son puestos por mandato del rey, pueden poner otros en sus lugares, que oigan, y libren aquellos pleitos señalados, que el rey les encomendare, quiera que sean comenzados ante ellos por demanda y por respuesta, quiera que no. Mas los otros delegados, a quienes los jueces ordinarios mandan oír y librar algunos pleitos señalados, no pueden poner otros que los libren en lugar de ellos; si primeramente no fueren comenzados por demanda, y por respuesta ante ellos. Otro sí decimos, que los delegados pueden oír pleitos, por mandamiento de aquellos que arriba dijimos, en dos maneras. La primera es, cuando les mandan oír, y librar algún pleito por sentencia. La segunda, cuando reciben mandamiento, de oirle tan solamente, reteniendo para sí el poderío de dar la sentencia, aquellos que se lo encomiendan. $Y$ cuando en esta segunda manera les fuere encomendado, débenlo ellos hacer así. Porque el poderío de los delegados no puede ser mayor, de cuanto les fuere otorgado por carta, o por palabra del rey, o de los otros sus superiores" (en Levaggi, 2005: 8-9).

26. AGN, Tribunales, Leg. 93, Exp. 11. IX - 36-7-2. 1785. Expediente formado sobre las dudas ocurridas en la inteligencia del art. 214 de la ordenanza general de intendentes, vistas del 26 de septiembre y 15 de diciembre de 1786 (en Levaggi, 1988: 196).

27. La Sala de Ordenanza estaba compuesta por tres oidores de la Real Audiencia con voto decisivo y dos contadores del Tribunal de Cuentas con voto informativo. En Buenos Aires esta se estableció en 1767 y estuvo conformada por el Contador Mayor, el gobernador y el Auditor de Guerra. En 1770 se ordenó que lo contencioso debía ser remitido a la Audiencia de Charcas. A partir de 1785 esta Sala de Ordenanza se conformó con los oidores de la Audiencia porteña elegidos por el Virrey (Rees Jones, 1992: 112).

28. "No se ha novedad en la práctica observada por el tribunal de cuentas antes del establecimiento de la Real Audiencia, sino que entienda que el espíritu de la instrucción en orden a los negocios de cuentas, está bien expresado y claro en las primeras palabras y últimas del citado artículo doscientos catorce, y conforme a él se debe mirarse el tribunal como el único propio de todos los negocios" AGN, Tribunales, IX 36-7-2 (en Levaggi, 1988: 204-205). imposibilitados enteramente de ejecutarlas por sí mismos, enviarán comisarios subdelegados de su entera satisfacción". ${ }^{24}$

El Superintendente de Real Hacienda con jurisdicción en la Intendencia de Buenos Aires, en carácter de juez ordinario, delegaba sus facultades para causas particulares, según todo resulta de las leyes. ${ }^{25}$ Frente a los desajustes en la tesorería aduanera de Montevideo se procedió a comisionar al administrador de la Real Aduana de Buenos Aires, Francisco Ximénez de Mesa. Bajo esta delegación Ximénez pasó a inspeccionar el estado de las cuentas, al mismo tiempo que los Contadores del Tribunal presentaban sus reclamos ante los miembros de la Junta Superior:

[...] confiesa el tribunal de cuentas el lleno de facultades de esta junta superior, y bajo de ese reconocimiento dice le ha consultado las dudas que le han ocurrido/ pertenecientes a la administración por mayor que en esta parte le está encargada a la misma junta por el mencionado art. 214 cuyos expedientes, añade, haberse despachado por el escribano de ella sin intervención del tribunal; pero que no son de esa clase los juicios de cuentas aunque se reduzca a justicia o en ellos se mezclen puntos de derecho porque estos pertenecen a la jurisdicción de los tribunales de cuentas con exclusión de todos los demás, de modo que en concepto de esta capital, la junta superior no tiene alguna para conocer de dichos juicios sino sólo para resolver las dudas que se le consultan en lo respectivo a la administración por mayor. ${ }^{26}$

Tal consulta fue resuelta a favor del Tribunal de Cuentas, se recordó que su majestad había fijado que tras el establecimiento de la Real Audiencia los asuntos de los juicios de cuentas pasaran por la Sala de Ordenanza ${ }^{27}$ y que los asuntos administrativos continuaran bajo la jurisdicción de la Superintendencia. En referencia al controversial artículo 214, el cual establecía que "nada sustancial ha de innovarse para con los erigidos en Buenos Aires eran competencias propias de este Tribunal", ${ }^{28}$ pudiendo actuar en la ejecución de deudas y cierre de cuentas. Tal resolución no pudo ser efectuada hasta 1788, año en el que se da la transformación en la Superintendencia.

Como se señala, las dinámicas de poder que se sucedieron tras la estructuración hacendaria de 1782 dieron cuenta de que las decisiones sobre los asuntos del erario real recayeron sobre el Superintendente. Los contrapesos institucionales presentes evidencian que estas no pudieron ejercer sus competencias hasta que se eliminó la figura del superior gobierno en materia fiscal. A partir de septiembre 1788, tras la eliminación de la superintendencia y la junta superior, los asuntos concernientes a los erarios reales volvieron a manos del Virrey y se conformó la Junta de Hacienda. Dicho cambio institucional posibilitará ejecutar las deudas de Quintana y dirimir los alcances de sus acciones por la vía contenciosa, como veremos a continuación.

\section{La comisión secreta sobre la tesorería aduanera de Montevideo}

El diseño institucional puesto en marcha en el Río de la Plata buscó concentrar las funciones de hacienda en una instancia superior de gobierno. En este proceso se observa que la organización hacendaria virreinal se dio de manera paulatina, y sobre la marcha de los asuntos se fueron ajustando las ordenanzas y reglamentaciones que marcaban la agenda de la corona. 
Entre 1778 y 1788 el superior gobierno hacendario quedó en manos de los Superintendentes. En un primer momento se destaca el accionar de Manuel Ignacio Fernández, quien diseñó e implementó las instituciones con sus competencias administrativas y jurisdiccionales sobre los asuntos concernientes a los erarios reales. ${ }^{29}$ Las acciones de Fernández establecieron un prototipo hacendario que quedó instrumentado a partir de 1782, con la puesta en vigencia de la RO de Intendentes. Esto trajo aparejado el reemplazo de Fernández por la llegada al cargo en la superintendencia de Francisco Paula de Sanz. Tales acciones de gobierno, en términos de Ernest Sánchez Santiró (2015: 124-133), se definirían como la constitucionalización de un nuevo orden institucional. Aquí se destaca que bajo la figura de Sanz se buscó uniformar los asuntos de gobierno poniéndolos bajo una sola cabeza rectora. ${ }^{30}$

A tan solo tres años de la aplicación de este orden institucional desde Montevideo el Gobernador del Pino, en carácter de Subdelegado de Superintendencia, informó sobre la imposibilidad de recaudar mes a mes las cuentas de la tesorería aduanera para ser remitidas a la capital. A este reclamo se le sumó la presión que ejercía el Tribunal de Cuentas. Las crecientes objeciones y presiones que encontraba Sanz a su gobierno hicieron que optase por conformar la comisión y por vía reservada se tratarán los motivos que causaron las demoras en cuentas de la tesorería aduanera. ${ }^{31}$

La visita del administrador de la Real Aduana de Buenos Aires, Francisco Ximénez de Mesa, se realizó entre el 23 de noviembre y el 27 de diciembre de 1786. El arribo de Ximénez como comisionado del Superintendente dio lugar a la intervención de la tesorería, privándole a Quintana el manejo de las entradas y salidas de esta aduana. Ximénez solicitó la asistencia del contador Josef Simón de Enseña y se dispuso a tomar conocimiento del estado de las cuentas. Tal pesquisa arrojó un faltante de 31.668 pesos, seis reales y cinco maravedís y otras deudas no cobradas a tiempo. Ximénez logró recuperar 17.779 pesos y cinco reales, resultando en contra de Quintana la suma de 13.869 pesos (Bentancur, 1985: 76).

Ante esta situación el Superintendente peticiona en la corte para no hacer cargos contra los desfalcos de Quintana, argumentando su delicado estado de salud. Estas consideraciones se contemplaron pero en 1787, tras la muerte del Ministro José de Gálvez, las circunstancias cambiaron. El nuevo ministro Antonio Valdés liberó una Real Orden el 7 de septiembre de 1788 para que se Ejecutase la quiebra. ${ }^{32}$ En el Río de la Plata había sido removido de su cargo Sanz, tras la reunificación de la Superintendencia con las competencias de hacienda en el Virrey. El marqués de Loreto, con plenas facultades sobre el gobierno hacendario, comisionó al gobernador Joaquín del Pino para dar arresto a Quintana y dar curso a su proceso. Para la administración de la aduana se nombró interinamente a Miguel de Luca y se dio curso al Tribunal de Cuentas para fenecer y finiquitar las deudas. ${ }^{33}$

Luego de las acciones correspondientes en diciembre de 1789 se formó el expediente por malversación contra el administrador de la Real Aduana de Montevideo, Antonio de Quintana Laso de la Vega. ${ }^{34}$ Su estudio permite conocer las acciones que desplegó el superior gobierno para contrarrestar el accionar del administrador. El expediente obrado arrojó una nueva indagación sobre el manejo de los caudales aduaneros. Con la revisión de las cuentas se dio paso a una reconsideración sobre la comisión de Ximénez. Estas acciones permitieron establecer el monto faltante y se procedió a saldar las deudas de comisos y particulares que ascendían a 13.867 para el mes de
29. Ver al respecto, Ravignani (1961: 103-104) y Levene (1927-1928] 1952).

30. Se propone la reconfiguración de la Real Hacienda novohispana entre 1781 y 1821 . Este trabajo busca mostrar la pluralidad que caracterizó a la cultura político fiscal y comprender los alcances y sentidos del proceso de constitucionalización del gobierno del erario regio a fines del periodo borbónico (Sánchez Santiró, 2015: 112-114).

31. La vía reservada le otorgaba al monarca la exclusividad en el conocimiento de los asuntos políticos, le permitía sortear los procesos de la vía consultiva en consejos para centralizar las decisiones y agilizar la administración de los asuntos concernientes a los erarios reales. (Moranchel Pocaterra, 2012: 437-448). En relación a ello para el caso de Indias, Anna Dubet (2018: 69) observa que esta vía no define el modelo político y la eficacia administrativa. El estudio de las relaciones de fuerza es lo que posibilita profundizar el conocimiento del modelo de gobierno hacendario desplegado -cuestión sobre la que se direcciona la profundización de este trabajo a futuro.

32. AGN. Criminales IX 32-4-6. Leg. 34. Exp. 4. Criminales. Superior Gobierno y Superior Intendencia General Subdelegada. Procedimientos en cumplimiento de la Real Orden del 7 de septiembre de 1788 , sobre la quiebra del Administrador de la RI. Aduana de Montevideo Don Antonio Quintana Lasso de la Vega. Año 1789.

33. Kraselsky (2017) plantea que a partir de 1783 la concentración unilateral del poder en manos del Superintendente generó mayores conflictos y concluye en un modelo político mixto, entre las pretensiones de la Corona y la conservación del control de las élites locales, entendido bajo la centralización corporativa.

34. AGN, Criminales, IX- 32-4-6. Leg. 34, Exp. 6. Expediente obrado para formalizar el procedimiento criminal contra el administrador de la Real Aduana de Montevideo Dn. Antonio de Quintana Laso de la Vega y los que resulten cómplices en la mala versación de los caudales en la aduana. Año 1789. 
35. Varios sujetos habían recibido caudales de la Tesorería a cargo de Quintana, entre ellos figuran: los 4.200 pesos de Sebastián Roso, los 2.070 pesos de Pedro Pablo Eugia y los 3.391 pesos del Teniente letrado de la intendencia de la Plata Francisco Cano de la Puerta. Profundizar sobre estos vínculos económicos habilitará a conocer las tramas relacionales en las que Quintana se insertó en la sociedad rioplatense. AGN, Criminales, IX-32-4-6. Leg. 34, Exp. 6. Año 1789.

36. AGN, Criminales, Leg. 34 Exp. 6 , IX-32-4-6. Año 1789. Foja 16.

37. AGN, Criminales, Leg. 34 Exp. 6, IX-32-4-6. Se recibe de los deudores Juan Manuel Salinas y Nicolás Lacort 13.879 para cubrir el descubierto y se recibieron 50 pesos que se le debe a Josef Simon Enseña. El señor fiscal en Montevideo estaba recibiendo dinero de los remates referidos a Eugia, 13.399 a favor Francisco Cano de la Puerta. Año 1789. Foja 226. marzo de $1789 .{ }^{35}$ De los cargos que se obraron contra Quintana se comprobó que utilizó los fondos de "la caja de aquella tesorería del Rey, que estaba a su cargo para beneficio de su persona, hijos, casa y otros particulares, haciéndole empréstitos de gruesas sumas en perjuicio de la Real Hacienda, malversando aquellos caudales" ${ }^{36}$ y que no debió haber dado moras a los comerciantes Lacort y Roso en sus pagos.

Para el 26 de marzo de 1792 Quintana presentó un estado de las deudas cobradas a favor de la Real Hacienda. Del alcance resultado en su contra había logrado cobrar 30.000 pesos, restando el cobro de otros 12.651 pesos, los que saldó con sus sueldos retenidos y entregas de otros deudores. ${ }^{37} \mathrm{El} 14$ de junio de 1793 el proceso de Quintana tuvo sentencia definitiva, su arresto cesó pero quedó inhabilitado de por vida para ejercer cargos al servicio del Rey.

El estudio sobre los estados contables en la aduana de Montevideo nos permite una aproximación a la realidad institucional que operó en la organización de gobierno y administración hacendaria. Se observa que bajo la constitucionalización del orden institucional a cargo de la Superintendencia de Hacienda, los excesos cometidos por Quintana fueron encuadrados bajo la lógica administrativa. Se puede reparar en que la ejecución de parte del desfalco y las deudas en contra de Quintana eran saldables y por lo tanto se le permitió continuar desempeñándose al frente de la administración.

Los cambios operados entre 1787 y 1788 llevaron a la revisión de las acciones del anterior gobierno, logrando ejecutar por la vía contenciosa las deudas del administrador. La reconsideración de los manejos de los caudales aduaneros se dio en términos de excesos de su jurisdicción, puesto que se logró comprobar la malversación con el desvío de fondos para fines personales y particulares; cuestión que se dirimió por la vía contenciosa estableciendo que dichos excesos se presentan como un acto criminal, en tanto que involucró a un servidor.

\section{Cierre}

En el recorrido de este trabajo se buscó dar una aproximación al funcionamiento del gobierno y la administración de la Real Hacienda Virreinal en la primera década de su existencia. Se observó que la Corona intentó dar al funcionamiento institucional una matriz más ejecutiva en pos de contener los asuntos del erario real bajo una cabeza de gobierno. Esto se tradujo en un andamiaje institucional que quedó bajo la figura del Superintendente con exclusiva jurisdicción en los asuntos hacendarios, en el cual se inscribió el gobierno de las Reales Aduanas.

Se mencionó el modelo de monarquía administrativa para explicar el accionar del Superintendente en el control y la supervisión de la tesorería de la Real Aduana de Montevideo. Esto se tradujo en la comisión a cargo de Ximénez de Mesa, quien procedió a ordenar el estado de los caudales aduaneros. Con la implementación de la RO de Intendentes se intentó llevar por la vía administrativa el gobierno hacendario. Frente a esta realidad, se observa que el accionar de los servidores se sostuvo entre las interpretaciones de la lógica administrativa y el componente jurisdiccional. Estas interpretaciones encontraron sus límites en la vía contenciosa, donde se dirimieron los alcances en los manejos de los caudales. 
Como se observó el proceso de organización del gobierno de la Real Hacienda se dio de forma paulatina y se caracterizó por el problema de competencias en las diferentes instancias que lo configuraban. En la corta duración de la Superintendencia se da el modelo administrativo en las aduanas. Luego de 1788, cuando la jurisdicción recae en la figura del Virrey el marqués de Loreto revisa la comisión y procede a enjuiciar a Quintana. Se plantea que el modelo de hacienda borbónica ensayado en el Río de la Plata en su intento administrativo encontró serios inconvenientes en el gobierno aduanero. El caso de Quintana posibilita conocer el avance de la corona y su relación con los interlocutores locales, presentando una continuidad en la arraigada cultura jurisdiccional del modelo Habsburgo.

En 1788 tras la reunificación de la superintendencia en el Virrey este recuperó sus competencias de gobierno hacendario. Los cambios políticos operados en la península tras la muerte del Ministro Gálvez dieron un nuevo marco interpretativo a las acciones de Quintana sobre el manejo de la tesorería aduanera. La revisión de la comisión obrada por Ximénez en 1786, llevó a dirimir por la vía contenciosa los alcances de los manejos de los fondos propios del erario real. Esta revisión establece la malversación de caudales llevando a la quiebra a Quintana, quien quedó inhibido de ocupar algún servicio para su majestad en 1796, a pesar de haber saldado sus deudas con el fisco real. En este contexto el Administrador Ximénez de Mesa, quien dos años antes fue designado juez comisionado, afrontó los mismos procedimientos y acusaciones que su par de Montevideo.

Al estudiar el caso de la aduana de Montevideo y el manejo de sus caudales bajo los renovados marcos explicativos que sustentaron las formas de gobernar y administrar los erarios regios, nos aproximamos a profundizar el conocimiento del sistema político implementado en América a fines del siglo XVIII. En este estudio reparamos en la pluralidad de actores institucionalizados que dieron forma al diseño hacendario, sin perder de vista que los servidores moldearon sus prácticas en los discursos jurídicos, los marcos normativos y la misma praxis que los sustentaban. También reparamos en la continuidad de una arraigada cultura jurisdiccional que se hizo presente en la justicia real.

A partir del estudio de las primeras experiencias administrativas en las aduanas reales se propone profundizar el conocimiento del modelo de gobierno hacendario. El encuadre político de este estudio de caso es una arista más en esta compleja realidad que se pretende profundizar, abordando las tramas institucionales y relacionales que sostuvieron a la Real Hacienda virreinal pero miradas desde las aduanas y sus servidores.

De esta forma, el estudio de caso aquí abordado nos aproxima al conocimiento de las estructura hacendaria y su funcionamiento en el Río de la Plata, sin perder de vista el manejo de la tesorería aduanera. Se observa el accionar de la Superintendencia como un intento de la monarquía de avanzar por la vía administrativa en 1782 y 1788. En este contexto, las ordenanzas que dieron forma al gobierno y al control de los recursos fiscales de la región fueron puestas en entredicho y revisadas, evidenciando nuevos ajustes al modelo hacendario. La profundización de este análisis aportará más elementos para conocer las formas que continuaron operando en América, luego de los ajustes ocurridos en las aduanas, iniciando un periodo de gobierno donde la hacienda quedó en manos del Virrey. 
15. De modo que aunque no hubiese una aduana, sí había controles aduaneros a través de la distribución de tareas entre diversos servidores reales. El Gobernador hacía las veces de jefe de aduanas, estableciendo o aplicando políticas en función de su jurisdicción sobre el tema. Entre las funciones de los Oficiales Reales estaban las de ser vistas de aduanas, inspectores y recaudadores, etc. En 1774 la creciente actividad mercantil registrada desde mediados del siglo llevó a la Corona a intentar instalar una Aduana en Buenos Aires, algo que no pudo ejecutarse por la resistencia de los actores locales. En 1777 el Gobernador Pedro de Cevallos estableció el auto de Libre Internación vía Buenos Aires-Potosí, que se reglamentó definitivamente en 1778. (En página 38).

17. Fue Intendente de la Armada y luego fue nombrado Superintendente de Hacienda (21 de marzo de 1778). También fue caballero de la Orden de Carlos III (23 de abril de 1780). En septiembre de 1785 se le concedió una plaza y se incorporó como ministro de capa y espada en el Consejo de Indias (1 de septiembre de 1785) hasta su muerte en 1790 (Diccionario Biográfico Electrónico, s/f). (En página 38).

21. Francisco Cabrera y Juan Francisco Navarro, ambos provenientes del Tribunal limeño. En 1780 fallece Navarro y en su lugar es nombrado Alejandro de Ariza, oficial de la Caja Real de Buenos Aires, quien conocía los pormenores del estado del erario real (Mariluz Urquijo, 1974: 139-144). (En página 38). 


\section{Fuentes consultadas}

"Archivo General de la Nación. Criminales, Sala IX 32-4-6. Leg. 34. Exp. 4. Criminales. Superior Gobierno y Superior Intendencia General Subdelegada. Procedimientos en cumplimiento de la Real Orden del 7 de septiembre de 1788, sobre la quiebra del Administrador de la Rl. Aduana de Montevideo Don Antonio Quintana Lasso de la Vega. Año 1789.

»Archivo General de la Nación, Criminales, Sala IX 32-4-6. Leg. 34, Exp. 6. Expediente obrado para formalizar el procedimiento criminal contra el administrador de la Real Aduana de Montevideo Dn. Antonio de Quintana Laso de la Vega y los que resulten cómplices en la mala versación de los caudales ella aduana. Año 1789.

》Diccionario Biográfico Electrónico (s/f). Real Academia de la Historia de España. Manuel Ignacio Fernández. Disponible en Internet: http://dbe.rah.es/biografias/75345/manuelignacio-fernandez. Consultada el: 5 de febrero de 2020.

》Diccionario Biográfico Electrónico (s/f). Real Academia de la Historia de España. Francisco de Paula Sanz. Disponible en Internet: http://dbe.rah.es/biografias/15356/francisco-depaula-sanz. Consultada el: 6 de enero de 2020.

》 Real Ordenanza para el establecimiento e instrucción de Intendentes de ejército y provincia en el Virreinato de Buenos Aires año de 1782. De orden de su Majestad. Disponible en Internet: Consultada el: 21 de marzo de 2020. https://es.wikisource.org/wiki/Ordenanza_de_ Intendentes_del_R\%C3\%ADo_de_la_Plata. Consultada el: 21 de marzo de 2020.

» Levaggi, A. (1988). El Virreinato rioplatense en las vistas fiscales de José Márquez de la Plata I: 195-199. Buenos Aires, Universidad del Museo Social Argentino. 


\section{Q Bibliografía}

" Agüero, A. (2006). Las categorías básicas de la cultura jurisdiccional. Cuadernos de Derecho Judicial 6: 19-58. (Ejemplar dedicado a De justicia de jueces a justicia de leyes: hacia la España de 1870).

" Barriera, D. (2006). Un rostro local de la Monarquía Hispánica: justicia y equipamiento político del territorio al sureste de Charcas, Siglos XVI-XVII. Colonial Latin American Historical Review 15 (4): 377- 418.

»Bentancur, A. (1985). Manuel Cipriano de Melo y Menezes. Montevideo, Arca.

» Brendecke, A. y M. Martín Romera (2017). El 'habitus' del oficial real: ideal, percepción y ejercicio del cargo en la monarquía hispánica (siglos XV-XVIII). Studia Historica: Historia Moderna 39 (1): 23-51. Disponible en https://revistas.usal.es/index.php/Studia_Historica/ article/view/16355. Consultada el: 8 de septiembre del 2020.

" Brading, D. A. (1990). “La España de los borbones y su imperio americano" en Bethell, L. (ed.); Historia de América Latina 2: 85-123. Barcelona, Crítica.

" Burkholder, M. A. y D. S. Chandler ([1977] 1984). De la impotencia a la autoridad. La Corona española y las Audiencias en América, 1687-1808. México, Fondo de Cultura Económica.

"Castejón, P. (2017). Reformar el imperio: el proceso de la toma de decisiones en la creación de las intendencias americanas (1765-1787). Revista de Indias LXXVII (271): 791-821. Disponible en Internet: http://revistadeindias.revistas.csic.es/index.php/ revistadeindias/article/view/1060\%3B. Consultada el: 1 de marzo de 2020.

»Clavero, B. (1982/83). "Hispanus fiscus, persona ficta. Concepción del sujeto político en el ius commune moderno". Quaderni Fiorentini per la storia del pensiero giuridico moderno 1 (11/12): 95-167. Disponible en Internet http://www.centropgm.unifi.it/cache/ quaderni/11/o096.pdf. Consultada el: 29 de abril de 2020.

" Conrad, R. y J. A. Gallego (1996). Las monarquías del Antiguo Régimen, imonarquías compuestas? Madrid, Editorial Complutense.

»Domínguez Orta, M. (2014). El sistema de intendencias indiano y el control de la real hacienda. El virreinato del río de la plata (1776 1782). Tesis Doctoral. Universidad Pablo de Olavide de Sevilla, Departamento de Economía Financiera y Contabilidad. Disponible en Internet: https://rio.upo.es/xmlui/bitstream/handle/10433/1531/manuela_ dom\% 3 \%ADnguez_tesis.pdf?sequence $=1$ \&isAllowed $=y$ Consultada el: 30 de abril de 2020.

" Domínguez Orta, M. (2016). "La regulación de las aduanas de Buenos Aires y Montevideo. Un ejemplo de control de los intendentes en asuntos de hacienda". Ponencia presentada en el X Congreso Iberoamericano de Contabilidad de Gestión y III Congreso Internacional sobre Gestión Portuaria. Departamento de Contabilidad, Facultat de Economía, Universitat de Valencia. Valencia, 27 al 29 de junio. Disponible en internet http://www.aeca1.org/premioefp/trabajos/2016/dominguez.pdf. Consultada el:-27 de abril de 2020.

»Dubet, A. (2018). El gobierno de las Haciendas Reales Hispánicas en el siglo XVIII: Dinámicas de los reformismos borbónicos. Magallánica, Revista de Historia Moderna 5 (9): 39-79. Disponible en Internet: https://fh.mdp.edu.ar/revistas/index.php/magallanica/ article/view/3122. Consultada el: 8 de octubre de 2020.

»Elliott, J. H. (1992). A Europe of Composite Monarchies. Past and Present 137: 48-71. 
» Galván Hernández, J. L. (2018). “La Junta Superior de Real Hacienda: establecimiento y consolidación (1786-1808)” en Celaya Nandéz, Y. y E. Sánchez Santiró (coords.); Hacienda e Instituciones. Los erarios regios, eclesiásticos y municipales en Nueva España: coexistencia e interrelaciones: 173-206. Ciudad de México. Instituto de Investigaciones Dr. José Luis María Mora/ Consejo Nacional de Ciencia y Tecnología/ Universidad Veracruzana.

» Garriga, C. (1997). Despotismo ilustrado y desorden social: la restauración de la Nueva Planta de la Audiencia de Cataluña (1775). Revista catalana d'historia del dret 2: 485-516.

» Garriga, C. (2004). Orden Jurídico y Poder Político en el Antiguo Régimen. Istor 16: 1-21.

» Gelman, J. (2000). “La lucha por el control del Estado: administración y elites en Hispanoamérica” en Tándeter, E. (dir.) y E. Hidalgo Lehuedé (codir.); Historia General de América Latina. Procesos americanos hacia la redefinición colonia IV: 251-264. España, Ediciones de la UNESCO/ Editorial Trotta.

» Irigoin, A. y R. Grafe (2008). Bargaining for Absolutism. A Spanish Path to Nation-State and Empire Building. Hispanic American Review 88 (2): 235-245.

» Jumar, F. (2012). “La región Río de la Plata y su complejo portuario durante el Antiguo Régimen” en Fradkin, R. O. (dir.); Historia de la Provincia de Buenos Aires. De la Conquista a la crisis de 1820 (2): 123-157. Buenos Aires, UNIPE/ EDHAS.

» Jumar, F. (2016). Las ‘reformas borbónicas’ en la formación de la historiografía argentina. Historia Caribe XI: 29, 113-154. Disponible en Internet: http://dx.doi.org/10.15648/ hc.28.2016.6. Consultada el: 30 de abril de 2020.

» Jumar, F. (2017). “El comercio rioplatense durante el Antiguo Régimen. Preguntas e hipótesis a la luz de la historiografía modernista contemporánea” Ponencia presentada en el XII Coloquio Internacional de Historia Europa y IX Jornadas de Estudios sobre la Modernidad Clásica. Departamento de Historia, Facultad de Humanidades, Universidad Nacional de Mar del Plata. Mar Del Plata, 29 de noviembre al 1 de diciembre.

» Kraselsky, J. (2012). De la centralización corporativa a la formación de Estados autónomos: aportes para un modelo analítico local. El caso del puerto Buenos Aires, 1779-1814 .Ponencia presentada en las Primeras Jornadas de Historia Económica. Asociación Mexicana de Historia Económica (AMHE). Ciudad de México, 8 al 10 de febrero. Disponible en http://www.amhe.mx/jornadas/ponencias2012/Kraselsky.pdf. Consultada el: 25 de mayo del 2020.

» Kraselsky, J. (2017). “La creación de las Intendencias de Ejército y Provincia en el Virreinato del Río de la Plata a fines del siglo XVIII. Algunos aportes para la conformación de un modelo político". Ponencia presentada en el XII Coloquio Internacional de Historiografía europea y IX Jornadas de estudios sobre la modernidad clásica. Universidad Nacional de Mar del Plata, Fac. de Humanidades, Depto de Historia. Mar Del Plata, 29 de noviembre al 1 de diciembre.

» Levaggi, A. (1988). El Virreinato rioplatense en las vistas fiscales de José Márquez de la Plata. Universidad del Museo Social Argentino, Buenos Aires. (Tomos I y II).

"Levaggi, A. (2005). Doctrinas de la segunda Audiencia de Buenos Aires (1785-1810). lushistoria 2. Disponible en Internet: http://p3.usal.edu.ar/index.php/iushistoria/. Consultado el: 15 de febrero de 2020.

"Levene, R. ([1927-1928] 1952). Investigaciones acerca de la Historia económica del Virreinato del Río de la Plata. Buenos Aires, El Ateneo. (2 vols., Segunda edición corregida y ampliada).

» Lynch, J. (1967). Administración colonial española 1782-1810. El sistema de intendencias en el Virreinato del Río de la Plata. Buenos Aires, EUDEBA. (Segunda edición).

» Mannori, L. (2007). Justicia y Administración entre el Antiguo y Nuevo Régimen. Revista 
Jurídica 15: 125-146. Disponible en Internet: http://hdl.handle.net/10486/4581. Consultada el: 20 de abril de 2020.

» Mannori, L. y B. Sordi (2001). Storia del diritto amministrativo. Laterzadi, Michele Spanò Storia.

» Mariluz Urquijo, J. M. ([1951] 2000). El Tribunal Mayor y Audiencia Real de Cuentas de Buenos Aires. Revista española de control externo 2 (4): 129-158.

» Mariluz Urquijo, J. M. (1974), Elenco de los Contadores Mayores (De número, supernumerarios, honorarios, substitutos y habilitados) de la Contaduría Mayor de Cuentas y del Tribunal Mayor de Cuentas de Buenos Aires (1767-1810). Investigaciones y Ensayos 16: 142-143.

" Moranchel Pocaterra, M. (2012). “El Consejo De Indias y su relación con la vía reservada en el reinado de Felipe V". Tesis Doctoral. Universidad Complutense de Madrid, Departamento de Historia del Derecho y de las Instituciones. Disponible en Internet: https://eprints.ucm.es/16579/. Consultada el: 20 de febrero de 2020 .

» Moriconi, M. (2011). Política, piedad y jurisdicción. Cultura jurisdiccional en la Monarquía Hispánica. Liébana en los siglos XVI-XVIII. Rosario, Prohistoria Ediciones.

" Moutoukias, Z. (1988). Burocracia, contrabando y auto-transformación de las élites de Buenos Aires en el siglo XVII. Anuario del IEHS 3: 213-248.

» Pietschmann, H. (1985). Burocracia y corrupción en Hispanoamérica colonial. Una aproximación tentativa. Nova América 5: 11-37.

"Pintos Bernal, J. y E. Sánchez Santiró (2016). El Reformismo Borbónico y pombalino: alcances y perspectivas. Historia Caribe XI: 29: 13-18. Disponible en Internet: http:// investigaciones.uniatlantico.edu.co/revistas/index.php/Historia_Caribe/issue/view/116/ showToc. Consultada el: 12 de marzo del 2020.

» Ravignani, E. (1961). “El virreinato del Río de la Plata (1776-1810)” en Levene, R. (dir.); Historia de La Nación Argentina IV: 99-113. Buenos Aires

"Rees Jones, R. (1987). Algunas repercusiones jurídicas de la difusión de la Ordenanza de Intendentes de Buenos Aires. Revista de Historia del Derecho 15: 405-432.

» Rees Jones, R. (1992). El Superintendente Manuel Ignacio Fernández (1778-1783). Las reformas borbónicas en el Virreinato de Buenos Aires. Buenos Aires, Instituto de Historia del Derecho.

» Sánchez Santiró, E. (2015). Constitucionalizar el orden fiscal en Nueva España: de la Ordenanza de Intendentes a la Constitución de Cádiz (1786-1814). Historia Mexicana 65 (1):111-165. Disponible en Internet: https://historiamexicana.colmex.mx/index.php/ RHM/article/view/3135. Consultada el: 26 de marzo de 2020.

"Socolow, S. ([1978] 1991). Los mercaderes del Buenos Aires virreinal: familia y comercio. Buenos Aires, Ediciones de la Flor.

» Storss, C. (2013). La pervivencia de la monarquía española bajo el reinado de Carlos II (1665-1700). Manuscritos 21: 39-61.

» Torres Sánchez, R. (2012). La llave de todos los Tesoros. La Tesorería General de Carlos III. Madrid, Silex.

» Torres Sánchez, R. (2013). El precio de la Guerra. El Estado fiscal-militar de Carlos III (17791783). Madrid: Marcial Pons.

»Vaccani, M. E. (2019). “Los servidores Reales en Río de la Plata: Las acciones de Francisco Ximenéz de Mesa en la Real Aduana de Buenos Aires. Una continuidad histórica en la dinámica institucional de la Monarquía, 1774-1788". Tesis de Maestría. Buenos Aires, 
Universidad Nacional de Tres de Febrero.

»Wasserman, M. L. E. (2018). Introducción al dossier “Gobierno y Administración de los Erarios de la Monarquía Hispana en las Indias, siglo XVIII". Anuario del Instituto de Historia Argentina 18 (2). Disponible en Internet: https://doi.org/10.24215/2314257Xeo71. Consultada el 24 de abril de 2020.

»Wasserman, M. L. E. (2020). Crédito para la frontera. Negociación institucional, coerción militar y financiación de la Real Hacienda en el Río de la Plata borbónico (1767-1777). Fronteras de la Historia 25 (1): 8-44. Disponible en Internet: https://doi. org/10.22380/20274688.66o. Consultada el: 8 de octubre de 2020.

»Yun Casalilla, B. (2009). “Introducción: entre el imperio colonial y la monarquía compuesta. Élites y territorios en la Monarquía Hispánica” en Yun Casalilla, B. (comp.); Las redes del imperio élites sociales en la articulación de la Monarquía Hispánica, 1492-1714: 11-35. Madrid, Marcial Pons.

»Zorraquín Becú, R. (1981). La Organización judicial Argentina en el periodo Hispánico. Buenos Aires, Facultad de Derecho y Ciencias Sociales Instituto de Historia del Derecho Ricardo Levene/ Ed. Perrot. (Segunda ed.). 